\title{
Neues 2-stufiges Poliersystem für Komposit-Füllungen
}

Das neue 2-stufige Poliersystem für Komposit-Füllungen bietet einen optimalen

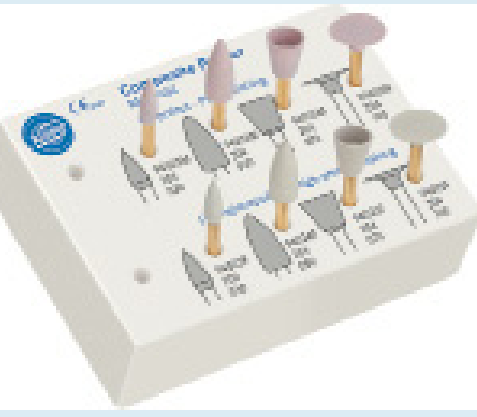

Mix aus Standzeit und Flexibilität. Nach der Formgebung durch Hartmetallfinierer erfolgt zunächst die Vorpolitur mit den hellrosa-farbenen Polierern. Die Diamantkörnung der Polierer ermöglicht Formkorrekturen, während gleichzeitig eine effektive Vorpolitur der Oberflächen stattfindet. Hellgelbe Polierer überneh- men anschließend die 2. Polierstufe und erzielen einen natürlich aussehenden Hochglanz. Der strahlende Glanz ist auf die feine Diamantkörnung zurückzuführen, die in eine spezielle Bindung eingelassen ist. Alle 8 Polierer überzeugen durch eine hohe Standzeit und sind im praktischen Starter-Set 4652 erhältlich. Mit dem 2-stufigen Poliersystem schließt Komet eine Lücke im Sortiment und lässt den Zahnarzt - je nach Präferenz - seinen individuellen Weg zur perfekten Oberfläche wählen.

Nach einer Pressemitteilung der Komet Dental Gebr. Brasseler GmbH \& Co KG, Lemgo

www.Im-dental.com/de 